\title{
Factors Associated with Perceived Susceptibility to COVID-19 Among Urban and Rural Adults in Alabama
}

\author{
Isabel C. Scarinci ${ }^{1,2}$ (1) $\cdot$ Vishruti N. Pandya $^{1} \cdot$ Young-il Kim $^{1,2} \cdot$ Sejong Bae ${ }^{1,2} \cdot$ Sylvia Peral $^{1} \cdot$ Meghan Tipre $^{1,2}$. \\ Claudia Hardy $^{2}$ Barbara Hansen ${ }^{1} \cdot$ Monica L. Baskin ${ }^{1,2}$
}

Accepted: 8 March 2021 / Published online: 22 March 2021

(c) The Author(s), under exclusive licence to Springer Science+Business Media, LLC, part of Springer Nature 2021

\begin{abstract}
We examined factors associated with and reasons for perceived susceptibility to COVID-19 among urban and rural adults in Alabama. We surveyed 575 eligible participants' engagement in preventive behaviors, concern about COVID-19 in their communities, perceived susceptibility to the virus, and reasons for susceptibility across three response options (Yes, No, and Don't Know/Not Sure). Bivariate analyses compared characteristics by level of perceived susceptibility to COVID-19. A multinomial logistic regression model evaluated the association of demographics, health insurance coverage, and chronic illness status with perceived susceptibility. Participants' race, gender, and educational attainment were significantly associated with perceived susceptibility to COVID-19. African Americans and males had higher odds of responding 'No', compared to 'Yes' and 'Don't Know/Not Sure' than Whites and females. Participants with a high school education and lower had higher odds of responding 'Don't Know/Not Sure' versus 'Yes' compared to those with college or higher education. Those unconcerned about COVID-19 in their community had higher odds of responding 'No' $(\mathrm{OR}=2.51, \mathrm{CI} 1.35-4.68)$ and 'Don't Know/Not Sure' $(\mathrm{OR}=2.51$, CI 1.26-4.99) versus 'Yes', as compared to those who were concerned. Possibility of exposure at work was the most frequent reasons for perceiving themselves susceptible to COVID-19, engagement in recommended preventive measures was the most frequent reason among respondents who indicated 'No', and uncertainty/perception that everyone is at risk was the most frequent reason among the ones who indicated 'Don't Know/Not Sure'. Results indicate that tailored efforts to heighten perceived susceptibility to COVID-19 among specific demographics are needed.
\end{abstract}

Keywords COVID-19 susceptibility $\cdot$ Minority health $\cdot$ Health Belief Model $\cdot$ Perceived susceptibility

\section{Introduction}

It became evident early on that COVID-19 had joined the litany of diseases with unequal health outcomes among racial/ethnic minorities, signaling that social factors, may be

Isabel C. Scarinci

scarinci@uab.edu

Vishruti N. Pandya

vnpandya@uabmc.edu

Young-il Kim

youngkim@uabmc.edu

Sejong Bae

sbae@uabmc.edu

Sylvia Peral

speral@uabmc.edu

Meghan Tipre

mtipre@uabmc.edu driving the disparities [1, 2]. As of early February, 2021, the U.S. has seen over 26 million COVID-19 infections, resulting in nearly 450,000 deaths, $15.4 \%$ of which were African Americans [3]. Alabama, with an infection rate of 9442 per 100,000, has seen over 465,000 cases and 8203 deaths from

Claudia Hardy

chardy@uab.edu

Barbara Hansen

barbarahansen@uabmc.edu

Monica L. Baskin

mbaskin@uabmc.edu

1 Division of Preventive Medicine, University of Alabama at Birmingham, 1717 11th Ave South, Birmingham, AL 35205, USA

2 O'Neal Comprehensive Cancer Center, University of Alabama at Birmingham, 1824 6th Ave South, Birmingham, AL 35233, USA 
the virus, with African Americans comprising $21 \%$ of cases and $28.4 \%$ of deaths [4].

The specific reasons for increased risk among African Americans and Latinx populations remain unclear. Answers may lie in varying social conditions, underlying comorbidities, or unidentified biological factors [5]. For example, these populations are more likely to live in poverty, lack health insurance, live in low-resource neighborhoods where they may have limited access to primary care, or work/live in crowded conditions that prevent physical distancing $[6,7]$. In addition, African Americans are disproportionately diagnosed with several chronic conditions, such as obesity, heart disease, diabetes, lung cancer, and kidney disease [8], which have been found to increase the risk of severe COVID-19 illness, hospitalization, and death [2, 9]. In their study of pandemic influenza during the H5N1 global outbreak, Blumenshine and colleagues linked increased vulnerability to existing health disparities, demonstrating that the social positions of racial/ethnic minorities may have led to disparities in three areas: (1) exposure to viral outbreaks, (2) susceptibility of developing serious virus-related illnesses, and (3) the medical treatment received [10]. Further, it has been shown that these marginalized populations may be hesitant to utilize the healthcare system due to mistrust $[11,12]$ and structured racism $[13,14]$.

When examining rural versus urban outcomes in COVID19 , the disparities are markedly evident when taking into consideration county-level data [2]. Alabama is one state that has experienced disparate outcomes in COVID-19, particularly in rural areas that are predominantly African American [4]. For example, in rural Perry County where $68.4 \%$ of the population is African American [15], the rate of COVID-19 infection is 11,599 per 100,000 persons [4]. In urban Mobile County where $33.4 \%$ of the population is African American [15], the rate of infection is 8095 per 100,000 [4]. It appears that African Americans in rural counties may face the double disparity of minority race and rural residence when it comes to COVID-19 outcomes.

There are several health precautions that individuals can take to avoid COVID-19 infection including frequent handwashing, wearing facial coverings, maintaining a six-foot distance between themselves and others, staying away from crowds, covering coughs and sneezes, and cleaning/disinfecting surfaces regularly [16]. Following these preventive measures and monitoring one's health each day can reduce the likelihood that an individual will contract COVID-19. Research has shown that when someone perceives themselves susceptible to a disease or illness, they are more likely to engage in preventive behaviors [17]. While past studies examined perceived susceptibility to various conditions such as tuberculosis [18], diabetes [19], and cancer [20], perceived susceptibility has not been extensively examined in COVID-19.
Most of the studies examining social factors related to the virus thus far focused on broad disparities among racial/ethnic minorities [2], took place in urban areas, examined testing rates and access [21], and the relationships between poor COVID-19 outcomes and comorbidities [9]. Few looked at perceived susceptibility to the virus. One study during the early onset of COVID-19 in the U.S. examined individuals' senses of preparedness and perceived susceptibility and found that African American adults, individuals living in poverty, and those with low levels of health literacy felt least prepared to deal with the pandemic and reported less perceived susceptibility to the virus [22]. However, this study was in a very large urban setting and occurred over a very short time in the early days of the pandemic with the first wave of the study taking place over 8 days in late March 2020 and the second wave occurring over the next 10 days (early April 2020). Their results showed that low levels of perceived susceptibility persisted; however, most reported changing plans to socialize with others and other health behaviors since the previous week, indicating that the recommendations regarding preventive measures such as frequent handwashing, social distancing, and wearing of face-masks in public were being followed.

There are critical gaps in research examining differences in perceived susceptibility to COVID-19, which our study hopes to fill in order to rapidly develop intervention strategies tailored to specific populations. Therefore, the purpose of this study is twofold: (1) to examine factors associated with perceived susceptibility to COVID-19 among urban and rural adults in Alabama; and (2) to identify perceived susceptibility reasons among participants.

\section{Methods}

\section{Overview}

This study is part of a larger collaboration among 17 National Institutes of Health, National Cancer Institutefunded Comprehensive Cancer Centers. The overall goal was to work together across these centers to rapidly assess the impact of the COVID-19 pandemic on engagement in cancer prevention behaviors (e.g., cancer screening, physical activity) and cancer management/survivorship behaviors (e.g., adherence to treatment) among adult community residents, cancer patients, and cancer survivors. The data presented in this paper reflect responses collected among community residents, not necessarily cancer patients and/ or survivors, in urban and rural areas in Alabama regarding their perceived susceptibility to COVID-19. 


\section{Theoretical Framework}

The theoretical framework guiding the study is the Health Belief Model (HBM), which suggests that an individual's change in health behaviors hinges on a series of beliefs, which include respondents': (1) perceived susceptibility to a condition or disease (e.g., exposure to COVID-19 infection); (2) perception that serious consequences could occur if they contract the disease (severe COVID-19 illness, hospitalization, and/or death); (3) perception that the benefits of the advised action outweigh the costs (e.g., inconvenience of preventive measures are worth not contracting COVID19); (4) perceived barriers to completing the action (e.g., affordability of masks, crowded workplace, little access to running water); (5) their acceptance of educational materials and other cues to action and belief that performing an action could reduce the risk of contracting the disease (e.g., wearing a face covering, social distancing, washing hands), and (6) the ability to complete the action required to prevent the disease (self-efficacy) [17].

\section{Setting}

The study took place in 12 counties in the state of Alabama: four urban and eight rural counties. Given the travel and social distancing restrictions associated with COVID-19, we focused data collection in urban and rural counties where the cancer center had local staff and/or existing relationships through previous/ongoing efforts. The counties are from different regions of the state and represent diversity with respect to rural/urban continuum codes, which ranged from 1 to 8 [23], percent of population that was African American, ranging from 3.2 to $71.4 \%$ [24], and percent of population living in poverty, ranging from 11.5 to $36.4 \%$ [15].

\section{Recruitment and Compensation}

Participants were recruited through existing contacts in the counties via referrals from the local Community Health Advisors as well as direct recruitment at local gas stations, grocery stores, etc. Participants were approached and asked if they were willing to participate in a COVID19 survey. The interviewer defined COVID-19 and stated that we were interested in how COVID-19 had affected health and wellbeing in our state. If the resident was interested, the interviewer provided an explanation of the study, determined eligibility, and gave participants the option of receiving the link to the online survey by email/text or of completing the survey over the phone. Once participants completed the survey, they were mailed a $\$ 25$ gift card. The inclusion criteria were being at least 18 years of age, and a resident in one of the participating counties. Only one participant was allowed per address and family. Data were collected between August and December 2020.

\section{Assessments}

The survey was developed in collaboration with four of the 17 comprehensive cancer centers who were part of the larger study. Data gathered included common measures assessing psychosocial and behavioral impacts of COVID-19 among community residents. These core measures focused on the following broad areas: work and employment, housing/home life, social activities, emotional well-being, physical health, and behaviors associated with recommended COVID-19 preventive measures (e.g., physical distancing, quarantine). Data were captured using Research Electronic Data Capture (REDCap) tools [25], which was compliant with guidelines from the Health Insurance Portability and Accountability Act.

Independent variables included: demographic characteristics (e.g., urban/rural residence, age, marital status, educational attainment, income, financial constraints), presence of chronic illnesses (heart disease, lung disease, liver disease, HIV, hypertension, diabetes, kidney disease, and cancer), and health insurance coverage. We also determined whether participants were concerned about COVID-19 in their communities (ranging from very concerned to not concerned at all) and their engagement in five COVID-19 prevention behaviors (wearing a face covering while inside a store or other place besides their homes; wearing a face covering when outdoors; staying six feet away from people when they left their homes; restricting friends, relatives, and neighbors from coming into their home; and staying home except for going to work/ outdoors to exercise/grocery store/medical appointments. The response options for behaviors were 'Yes,' 'No,' and 'Don't Know/Not Sure' (DK/NS). The social distancing/ preventive COVID-19 behaviors were combined to create a "Social Distancing Score" by counting the number of 'Yes' responses to these five behavior questions with an estimated Social Distancing Score range from 0 (no preventive behaviors) to 5 (all preventive behaviors).

The dependent variable was whether participants perceived themselves susceptible to COVID-19 ("Do you think you are at risk of being infected with COVID-19?"). Response options were 'Yes,' 'No,' and 'DK/NS'. Participants were also asked to explain why they answered the way they did in a text box. Participants were also asked if they had been tested for COVID-19 and if they had tested positive. Participants who reported testing positive were excluded from analyses. 


\section{Statistical Analysis}

Demographic characteristics, health insurance coverage, confidence in the ability to take care of one's own health, concern of coronavirus in the community, and chronic illness status for the study participants were summarized for each status of perceived susceptibility to COVID-19 by using descriptive statistics. ANOVA or chi-square tests were used to compare these characteristics among different levels of perceived susceptibility to COVID-19. A multinomial logistic regression model was used to evaluate the association of demographics, health insurance coverage, concern of coronavirus in the community and chronic illness status with perceived susceptibility to COVID-19. The estimated odds ratios were probabilities of responding 'No' and 'DK/NS' compared to 'Yes' for perceived susceptibility to COVID-19 separately. We made the decision to include the 'DK/NS' response as a separate choice because this response may not indicate response ambivalence but rather a lack of knowledge about a topic [26]. As found in previous cancer research, a 'DK/NS' response can be accounted for by a respondent's lack of knowledge and level of education, which can be addressed by incorporating educational components into interventions [27, 28]. Detailed reasons for perceiving susceptibility to COVID-19 were listed with frequencies and proportions. All statistical analyses were performed by utilizing SAS 9.4 [29]. Statistical significance was defined at $p<0.05$.

\section{Results}

\section{Demographics}

Of the 616 participants completing the survey, one was excluded due to a missing observation for the outcome variable, measured perceived susceptibility to COVID-19. Also excluded from analyses were 40 participants who reported having tested positive for COVID-19. Thus, the study analytic sample was comprised of 575 participants. The mean age for the overall sample was $43.35( \pm 15.65)$ years and the majority were female (73.7\%). Whites comprised $48 \%$ and African Americans $44.6 \%$ of participants. With a combined annual income of $\$ 75,000$ or higher (34.7\%), $46.8 \%$ of participants had at least a college degree, felt their household financial situation was such that they had enough money to pay their bills and have enough left for "special things" (38.2\%), were married or living with a partner (51.5\%), lived in an urban county $(58.3 \%)$, had health insurance coverage (89.1\%) and reported no chronic illnesses (54.1\%).

As seen in Table 1 and $44.9 \%$ answered 'Yes' to the question "Do you think you are at risk of being infected with COVID-19?" while $34.3 \%$ answered 'No' and $20.9 \%$ answered 'DK/NS.' The mean social distancing score was $3.9( \pm 1.18)$. Those perceiving susceptibility to the virus were predominantly White, had at least a college degree, felt 'Completely confident' (27.7\%) or 'Very confident' (43.9\%) in their ability to take care of their health, and 'Very concerned' (45.7\%) or 'Concerned' (36.1\%) about COVID-19 in their community. Those responding 'No' to perceived susceptibility to COVID-19 were majority non-Hispanic African American; had a high school or lower educational attainment; felt 'Completely confident' or 'Very confident' in their ability to take care of their health; and were less concerned about COVID-19 in their communities than those perceiving a risk or those who were unsure. Among those who responded 'DK/NS' to perceived susceptibility to COVID-19, the majority were non-Hispanic White, had some college, and felt 'Very confident' in their ability to take care of their health. When looking at gender, a higher proportion of women perceived susceptibility to COVID-19, compared to not perceiving susceptibility or responding with 'DK/NS'. More men, on the other hand, felt they were not susceptible to the virus in comparison to perceiving susceptibility or not being sure $(p<0.05)$.

Multinomial logistic regression analysis (Table 2) showed that non-Hispanic Whites had lower odds than non-Hispanic African Americans of responding with 'No' compared to 'Yes' ( $\mathrm{OR}=0.34$, CI 0.20-0.59). Also, females were less likely to respond with 'No' compared to 'Yes' than males $(\mathrm{OR}=0.47$, CI 0.28-0.78). Participants with a high school/ GED degree or lower had higher odds of responding with 'DK/NS' versus 'Yes' compared to those with a college degree or higher $(\mathrm{OR}=0.37, \mathrm{CI} 0.16-0.85)$. Those who were 'Not at all concerned/Concerned a little/Neither concerned nor unconcerned' about coronavirus in their community had higher odds of saying 'No' $(\mathrm{OR}=2.51, \mathrm{CI} 1.35-4.68)$ and 'DK/NS' $(\mathrm{OR}=2.51$, CI 1.26-4.99) versus 'Yes', as compared to those who were 'Concerned/Very concerned.'

The most common reason given for responding 'Yes' to perceived susceptibility was 'Possibility of exposure at work' (42.6\%). Among those who said 'No,' the most common reason was 'Engagement in the recommended COVID19 measures' (44.4\%), while those who responded with 'DK/ NS' reported the 'Perception that everyone is at risk/uncertainty about exposure' $(43.0 \%)$ as the most frequent reason (Table 3).

\section{Discussion}

Our study provided valuable insight into perceptions of susceptibility to COVID-19. These insights will be important in designing interventions intended to address COVID-19 testing, prevention measures, education, and vaccination. While bivariate analyses did not reveal significant associations 
Table 1 Participants' characteristics by perceived susceptibility to COVID-19 ( $\mathrm{N}=575)$

\begin{tabular}{|c|c|c|c|c|c|}
\hline Characteristic & Total & $\begin{array}{l}\text { Yes } \\
(n=258)\end{array}$ & $\begin{array}{l}\text { No } \\
(n=197)\end{array}$ & $\begin{array}{l}\mathrm{DK} / \mathrm{NS} \\
(\mathrm{n}=120)\end{array}$ & p-value \\
\hline $\operatorname{Age}^{\mathrm{a}}$ (years) & 562 & $42.74 \pm 15.08$ & $43.35 \pm 16.04$ & $44.70 \pm 16.27$ & 0.5412 \\
\hline \multicolumn{6}{|l|}{ Race $^{\mathrm{b}}$} \\
\hline White & 269 & 53.90 & 23.42 & 22.68 & \multirow[t]{3}{*}{$<0.0001$} \\
\hline African American & 250 & 36.40 & 44.40 & 19.20 & \\
\hline Other including Hispanic & 41 & 41.46 & 39.02 & 19.51 & \\
\hline \multicolumn{6}{|l|}{ Hispanic ethnicity ${ }^{c}$} \\
\hline Yes & 20 & 45.00 & 45.00 & 10.00 & \multirow[t]{2}{*}{0.3921} \\
\hline No & 548 & 45.07 & 33.76 & 21.17 & \\
\hline \multicolumn{6}{|l|}{ Gender ${ }^{b}$} \\
\hline Male & 150 & 38.00 & 42.67 & 19.33 & \multirow[t]{2}{*}{0.0340} \\
\hline Female & 421 & 47.51 & 31.12 & 21.38 & \\
\hline \multicolumn{6}{|l|}{ Educational attainment ${ }^{\mathrm{b}}$} \\
\hline$\leq$ High school/GED & 121 & 33.88 & 40.50 & 25.62 & \multirow[t]{3}{*}{0.0118} \\
\hline Some college & 184 & 45.65 & 29.35 & 25.00 & \\
\hline$\geq$ College degree & 268 & 49.25 & 34.70 & 16.04 & \\
\hline \multicolumn{6}{|l|}{ Annual income ${ }^{b}$} \\
\hline$\$ 0$ to $\$ 19,999$ & 81 & 32.10 & 38.27 & 29.63 & \multirow[t]{4}{*}{0.1926} \\
\hline$\$ 20,000$ to $\$ 49,999$ & 128 & 45.31 & 34.38 & 20.31 & \\
\hline$\$ 50,000$ to $\$ 74,999$ & 118 & 48.31 & 31.36 & 20.34 & \\
\hline$\$ 75,000+$ & 174 & 50.57 & 29.31 & 20.11 & \\
\hline \multicolumn{6}{|l|}{ Financial situation right now ${ }^{\mathrm{b}}$} \\
\hline After paying the bills, you have enough money for special things that you want. & 216 & 50.93 & 30.56 & 18.52 & \multirow[t]{4}{*}{0.2740} \\
\hline You have money to pay the bills, but little extra & 191 & 42.93 & 32.98 & 24.08 & \\
\hline You have money to pay bills because you cut back on things you want & 97 & 38.14 & 39.18 & 22.68 & \\
\hline You have difficulty paying the bills no matter what you do & 62 & 43.55 & 40.32 & 16.13 & \\
\hline \multicolumn{6}{|l|}{ Marital status ${ }^{b}$} \\
\hline Married/living with a partner & 295 & 47.80 & 30.51 & 21.69 & \multirow[t]{2}{*}{0.1262} \\
\hline Single/separated/divorced/ widowed/other & 278 & 41.37 & 38.49 & 20.14 & \\
\hline \multicolumn{6}{|l|}{ Urban/rural region ${ }^{\mathrm{b}}$} \\
\hline Urban & 335 & 45.07 & 35.52 & 19.40 & \multirow[t]{2}{*}{0.5468} \\
\hline Rural & 240 & 44.58 & 32.50 & 22.92 & \\
\hline \multicolumn{6}{|l|}{ Health insurance coverage ${ }^{b}$} \\
\hline Yes & 509 & 46.37 & 33.60 & 20.04 & \multirow[t]{2}{*}{0.1707} \\
\hline No & 62 & 33.87 & 40.32 & 25.81 & \\
\hline \multicolumn{6}{|l|}{ Chronic illness ${ }^{b}$} \\
\hline Present & 258 & 45.35 & 32.56 & 22.09 & \multirow[t]{2}{*}{0.7187} \\
\hline Absent & 304 & 44.41 & 35.53 & 20.07 & \\
\hline \multicolumn{6}{|l|}{ Confidence in ability to take care of health ${ }^{\mathrm{b}}$} \\
\hline Completely confident & 189 & 37.04 & 46.56 & 16.40 & $<0.0001$ \\
\hline Very confident & 247 & 44.94 & 32.39 & 22.67 & \\
\hline Somewhat confident & 119 & 54.62 & 19.33 & 26.05 & \\
\hline A little confident & 10 & 50.00 & 30.00 & 20.00 & \\
\hline Not confident at all & 2 & 100.00 & - & - & \\
\hline Concerned about COVID-19 in community ${ }^{\mathrm{b}}$ & & & & & \\
\hline Not at all concerned & 18 & 16.67 & 61.11 & 22.22 & 0.0412 \\
\hline Concerned a little & 82 & 45.12 & 34.15 & 20.73 & \\
\hline Neither concerned nor unconcerned & 32 & 21.88 & 43.75 & 34.38 & \\
\hline Concerned & 191 & 48.69 & 31.94 & 19.37 & \\
\hline Very concerned & 250 & 47.20 & 33.20 & 19.60 & \\
\hline Social distancing score ${ }^{\mathrm{a}}$ & 547 & $3.82 \pm 1.18$ & $4.07 \pm 1.10$ & $3.85 \pm 1.29$ & 0.0628 \\
\hline
\end{tabular}

ANOVA for continuous variables, Pearson chi-square for categorical variables. Bold typeface indicates statistical significance

$D K / N S$ Don't know/Not sure

${ }^{\mathrm{a}}$ Mean (SD)

${ }^{\mathrm{b}}$ Percentage 
Table 2 Multinomial logistic regression models of factors associated with perceived susceptibility to COVID-19

\begin{tabular}{|c|c|c|}
\hline & No & Don't Know/Not Sure \\
\hline Age & $1.015(0.997-1.033)$ & $1.012(0.991-1.032$ \\
\hline \multicolumn{3}{|l|}{ Race $^{\mathrm{a}}$} \\
\hline Non-Hispanic Whites & $0.341(0.198-0.586)$ & $0.675(0.367-1.242)$ \\
\hline Other (including Hispanic) & $0.621(0.249-1.547)$ & $0.647(0.212-1.971)$ \\
\hline \multicolumn{3}{|l|}{ Gender $^{\mathrm{b}}$} \\
\hline Female & $0.469(0.281-0.784)$ & $0.825(0.444-1.534)$ \\
\hline \multicolumn{3}{|l|}{ Educational attainment $^{\mathrm{c}}$} \\
\hline Some college & $0.762(0.378-1.538)$ & $0.933(0.446-1.951)$ \\
\hline$\geq$ College degree & $0.871(0.418-1.818)$ & $0.366(0.158-0.849)$ \\
\hline \multicolumn{3}{|l|}{ Annual income ${ }^{\mathrm{d}}$} \\
\hline$\$ 20,000$ to $\$ 49,999$ & $0.730(0.324-1.641)$ & $0.532(0.216-1.314)$ \\
\hline$\$ 50,000$ to $\$ 74,999$ & $0.631(0.253-1.576)$ & $0.695(0.258-1.867)$ \\
\hline$\$ 75,000$ and higher & $0.676(0.254-1.801)$ & $0.727(0.251-2.106)$ \\
\hline \multicolumn{3}{|l|}{ Financial situation right now ${ }^{\mathrm{e}}$} \\
\hline You have money to pay the bills, but little extra & $1.365(0.774-2.406)$ & $1.313(0.701-2.456)$ \\
\hline You have money to pay bills because you cut back on things you want & $1.476(0.707-3.080)$ & $1.043(0.464-2.345)$ \\
\hline You have difficulty paying the bills no matter what you do & $1.217(0.484-3.061)$ & $0.314(0.092-1.067)$ \\
\hline \multicolumn{3}{|l|}{ Marital status ${ }^{\mathrm{f}}$} \\
\hline Married/living with a partner & $0.961(0.572-1.615)$ & $0.832(0.460-1.504)$ \\
\hline \multicolumn{3}{|l|}{ Urban/rural region ${ }^{\mathrm{g}}$} \\
\hline Rural & $0.858(0.500-1.471)$ & $0.844(0.461-1.546)$ \\
\hline \multicolumn{3}{|l|}{ Health insurance coverage ${ }^{\mathrm{h}}$} \\
\hline Yes & $0.744(0.334-1.658)$ & $0.691(0.278-1.716)$ \\
\hline \multicolumn{3}{|l|}{ Chronic illness ${ }^{\mathrm{i}}$} \\
\hline Present & $0.659(0.380-1.140)$ & $0.920(0.494-1.713)$ \\
\hline \multicolumn{3}{|l|}{ Concerned about COVID-19 in community ${ }^{j}$} \\
\hline Not at all concerned/Concerned a little/Neither concerned nor unconcerned & $2.511(1.348-4.676)$ & $2.511(1.263-4.993)$ \\
\hline Social distancing score & $1.130(0.891-1.433)$ & $1.064(0.819-1.381)$ \\
\hline
\end{tabular}

Odds Ratio (95\% CI); p-value $<0.05$; boldface type indicates statistical significance

${ }^{a}$ Reference group: Non-Hispanic African American

${ }^{\mathrm{b}}$ Reference group: male

${ }^{\mathrm{c}}$ Reference group: $\leq$ high school/GED

${ }^{\mathrm{d}}$ Reference group: $\$ 0$ to $\$ 19,999$

${ }^{\text {e}}$ Reference group: after paying the bills, you have enough money for special things that you want.

${ }^{\mathrm{f}}$ Reference group: single/separated/divorced/ widowed/other

${ }^{g}$ Reference group: urban

${ }^{\text {h}}$ Reference group: no

${ }^{\mathrm{i}}$ Reference group: absent

${ }^{\mathrm{j}}$ Reference group: concerned/very concerned

between perception of susceptibility and social variables, such as age, marital status, and income, there were significant differences by race, gender, and educational attainment, echoing results from previous studies of susceptibility to various diseases [30, 31]. The decision to include a category reflecting uncertainty of risk was an important one as we were able to identify significant variables associated with this perception.
Our finding that African Americans were significantly less likely to perceive they were at risk of COVID-19 infection than their White counterparts mirrors similar perceptions during the $\mathrm{H} 5 \mathrm{~N} 1$ and H1N1 outbreaks, where trust was cited as the driver of these perceptions [32,33]. Plough et al. explained that mistrust of the government and the messages from public health institutions exacerbated lack of perceived risk, which can be problematic, particularly when it comes to vaccine uptake, 
Table 3 Most frequent reasons for perception of COVID-19 susceptibility

\begin{tabular}{|c|c|}
\hline Reasons & Frequency $(\%)$ \\
\hline \multicolumn{2}{|l|}{ Yes $(\mathrm{N}=237 \text { reasons })^{\mathrm{a}}$} \\
\hline Possibility of exposure at work & $101(42.6)$ \\
\hline Perception that everyone is at risk/uncertainty about exposure & $60(25.3)$ \\
\hline Presence of chronic illnesses & $24(10.1)$ \\
\hline Leaving the house for errands and other gatherings/around people & $23(9.7)$ \\
\hline Others not adhering to recommendations & $19(8.0)$ \\
\hline Other reasons (age, race) & $10(4.2)$ \\
\hline \multicolumn{2}{|l|}{ No $(\mathrm{N}=160 \text { reasons })^{\mathrm{a}}$} \\
\hline Engaging in the recommended COVID-19 measures (e.g., social distancing, wearing a mask, handwashing) & $71(44.4)$ \\
\hline Limiting social interactions/staying & $56(35.0)$ \\
\hline Being heathy/"strong immune system"/not feeling sick or having symptoms & $14(8.8)$ \\
\hline Not knowing anyone who had COVID-19/not exposed & $5(3.1)$ \\
\hline $\begin{array}{l}\text { Other reasons: included being young, "fatalistic' explanations (e.g., "being covered by the blood of Jesus, "being a positive } \\
\text { thinker/what you think, you become"), having been tested for COVID-19, mistrust/disbelief (e.g., "I feel the numbers are } \\
\text { misleading" and "It is blown out of proportion") }\end{array}$ & $10(6.3)$ \\
\hline \multicolumn{2}{|l|}{ Don’t Know/Not Sure $(\mathrm{N}=86 \text { reasons })^{\mathrm{a}}$} \\
\hline $\begin{array}{l}\text { Perception that everyone is at risk/uncertainty about exposure (e.g., "Everyone is at risk" and "I am taking the precautions, but } \\
\text { anything can happen") }\end{array}$ & $37(43)$ \\
\hline Potential exposure at work & $23(26)$ \\
\hline Being around people (e.g., children/grandchildren, going to the grocery store) & $9(10.4)$ \\
\hline Other reasons included: having a chronic illness, family member working in healthcare, "not sure", "haven't caught it yet" & 17 (19.8) \\
\hline
\end{tabular}

${ }^{a}$ If participants provided more than one reason, reasons were counted separately. The $\mathrm{N}$ reflects the number of reasons and not the number of participants

evident in 2009 during the H1N1 pandemic [32]. As well, the perception of susceptibility to COVID-19 is an important first step in the HBM [17]. Without perceiving risk, a person's understanding that they could become seriously ill or die from the virus as well as their acceptance of educational materials and the need for undertaking preventive measures could be impaired. Unfortunately, even though we have a greater understanding of risk perception, the problem of engendering trust among racial/ethnic minorities has not improved enough since the earlier influenza pandemics and is contributing to racial/ ethnic health disparities during the COVID-19 pandemic.

There were also significant differences in perception of risk by gender with men less likely to perceive they were at risk compared to women. This finding is similar to Ibuka and colleagues' results from their study on risk perception and precautionary behaviors during the $2009 \mathrm{H} 1 \mathrm{~N} 1$ influenza pandemic [34]. The researchers found that, not only were women more likely to perceive risk of the virus, they were more likely to seek information about $\mathrm{H} 1 \mathrm{~N} 1$, engage in preventive measures, and to use pharmaceutical interventions than men. As well, during the SARS outbreak in 2003, Brug et al. found that women were more likely to perceive susceptibility to viral outbreaks than men [35]. Our finding that women during COVID19 also perceive higher levels of susceptibility is not unusual in that women tend to be more concerned over their health and the health of their families, and tend to seek medical care more frequently than men [36]. Previous research has shown that female partners/wives have a tremendous influence on men's preventive health behaviors [37]. In fact, according to Gast and Peak, when wives encouraged their husbands to engage in health-promoting behaviors, a perceived loss of masculinity on the husband's part becomes more palatable [38]. The researchers suggested that the traditional gender script of not seeking medical help that many men follow seemed less important than making their wives happy. This characteristic might be capitalized upon when designing educational and vaccinations interventions for COVID-19 for men.

Further examination of our results revealed that when compared to participants with a college degree or higher, those with a high school education or less were much more likely to not know their risk of infection versus knowing their risk. Educational attainment is positively associated with both engagement in healthy behaviors [39] and health literacy scores [40]. While our study did not measure health literacy, it may explain our sample's identification of risk of COVID-19 infection. There is evidence, though, that health literacy can mediate the relationship between lower levels of education and engaging in unhealthy behaviors [41], which can become a focal point in interventions.

Concerns about community spread exposed one of the more significant differences between those who did not know or were not sure of their risk and those who perceived 
risk of COVID-19 infection. Unconcerned participants had far higher likelihood of being unsure of their risk, which could be problematic when it comes to practicing prevention behaviors. The underlying factor in this relationship is the understanding of risk. Harper and colleagues examined factors associated with compliance with community virusmitigating behaviors [42]. After considering a variety of possible predictors, including political orientation and moral foundations, they found that fear of COVID-19 was the only predictor of positive behavior changes in personal and community settings. For those in our study who were unsure of their risk of infection, it is not surprising they were unconcerned about community spread as they, quite possibly, did not understand the disease enough to fear its effects. It is also possible that misinformation about the virus played a part in their uncertainty about risk levels.

It was notable that participants perceiving they were not at risk believed they were safe because they engaged in preventive measures, stayed home, and limited social interactions. In comparison, among those who felt they were at risk, the two most frequent reasons given were the possibility of exposure at work and the perception that "everyone is at risk" and "...anything can happen." The latter was also the most frequent reason given among those who did not know about their perceived susceptibility to COVID-19. Bateman et al. found that African Americans from underresourced communities working in lower-paying retail work were very concerned about contracting COVID-19 [43]. As well, uncertainty about risk may result from difficulty in social distancing in service-sector jobs and in companies that restructured their business model to incorporate delivery options [44]. As the knowledge about COVID-19 evolved over the past year, the messaging regarding risk has also evolved, becoming politically polarized, and possibly leading to more uncertainty resulting in a lack of trust in public health recommendations, misconceptions, or beliefs in conspiracy theories [45]. In future outbreaks, it will be important for public health institutions to be consistent in messaging to increase the public's trust.

According to the HBM [17], individuals who perceive COVID-19 as a threat that might lead to hospitalization or death will be more likely to practice preventive behaviors. Our findings regarding which populations perceived, did not perceive, or were not sure about their susceptibility are important to guide future intervention development. For example, if our target audience is African American, we know that, at least in Alabama, participants might be less likely to perceive susceptibility than White counterparts and our approach should rely on evidence-based, culturally relevant methods to educate them on COVID-19 transmission and high-risk behaviors. The end goal of a behavioral intervention is self-efficacy and helping participants learn that they are able to perform preventive actions by acknowledging barriers and providing resources to overcome them. The differences between 'Yes' and 'DK/NS' in educational attainment and concerns about COVID-19 in their communities played an important role in participants not knowing their risk, which is conceptualized differently than answering 'Yes' or 'No', which suggests that dissemination of easy-to-read information may be a potential strategy to heighten risk, and consequently, promote protective behavior among individuals with limited educational attainment.

Our study was unique in that we evaluated both urban and rural residents' perceptions of susceptibility to COVID-19. Other studies in perceived susceptibility to COVID-19 were either in urban areas or did not differentiate between urban and rural $[46,47]$, leaving us to wonder if risk perceptions varied. We found no significant differences between perceived susceptibility to COVID-19 and rural/urban location of residence. This is an important finding in that future educational interventions designed for urban residents may be just as effective in rural areas.

\section{Study Strengths and Limitations}

This study has some limitations that should be mentioned. First, the obtained data are based on self-report among a convenience sample, given the pandemic restrictions. Second, the pandemic was an evolving phenomenon with new information and discoveries being released by the government and other agencies on an ongoing basis during the recruitment months, which could impact perceived susceptibility to COVID-19 at a particular point in time. However, it should be noted that state and local mandates related to the pandemic did not change during the recruitment period. For instance, Alabama mandated facial coverings in July 2020 and the mandate is still in effect as of February 2021.

\section{Conclusions}

Our study demonstrates there are differences between those who perceive they are susceptible to COVID-19 and those who do not or are unsure. Men, African Americans, and those who are not concerned about COVID-19 in their communities were more likely to believe they are not susceptible while their counterparts believed they were. Longitudinal studies are needed to better understand changes in perceptions with regard to testing and vaccination as the pandemic continues.

Acknowledgements Authors appreciate the support from the staff, especially the local Community Coordinators at the O'Neal Comprehensive Cancer Center and Division of Preventive Medicine, who were instrumental in the recruitment of research participants. We are also very thankful to Drs. Shoba Srinivasan, Amy Kennedy, Evelinn Borrayo, Electra Paskett, Mary Charlton, Hayley Thompson, Elizabeth 
Chrischilles, and Jamie Studts who were true partners in the development of the assessment tool.

Author's Contribution IS: Conceptualization, Methodology, Investigation, Writing-Review \& Editing, Supervision. VNP: Conceptualization, Data Management, Formal Analysis, Writing-Review \& Editing. Y-iK: Conceptualization, Methodology, Investigation, Formal Analysis, Writing-Review \& Editing. SB: Conceptualization, Methodology, Investigation, Formal Analysis, Writing-Review \& Editing. SP: Conceptualization, Methodology, Project Administration, Writing-Review \& Editing. MT: Conceptualization, Methodology, Investigation, Writing-Review \& Editing. CH: Conceptualization, Methodology, Staff Supervision, Writing-Review \& Editing. BH: Writing-Review \& Editing, Final Formatting and Organization. MLB: Conceptualization, Methodology, Investigation, Writing-Review \& Editing, Supervision.

Funding This study was funded by the National Cancer Institute (Grant \# P30CA013148).

\section{Declarations}

Conflict of interest The authors declare that they have no conflict of interest.

Ethical Approval The study was approved through the institutional review board at the University of Alabama at Birmingham. The study was performed in accordance with the Declaration of Helsinki.

Informed Consent A waiver of written consent was obtained through the institutional review board at the University of Alabama at Birmingham (UAB).

\section{References}

1. Marmot, M., \& Allen, J. (2020). COVID-19: Exposing and amplifying inequalities. Journal of Epidemiology and Community Health, 74(9), 681-682.

2. Mahajan, U. V., \& Larkins-Pettigrew, M. (2020). Racial demographics and COVID-19 confirmed cases and deaths: A correlational analysis of 2886 US counties. Journal of Public Health. https://doi.org/10.1093/pubmed/fdaa070.

3. Centers for Disease Control and Prevention. (2021). Cases of coronavirus (COVID-19) in the United States. Retrieved February 4, 2021, from https://www.cdc.gov/coronavirus/2019-ncov/ need-extra-precautions/racial-ethnic-minorities.html.

4. Alabama Department of Public Health. (2021). Alabama's COVID-19 data and surveillance dashboard. Retrieved February 4, 2021, from https://alpublichealth.maps.arcgis.com/apps/opsda shboard/index.html\#/6d2771faa9da4a2786a509d82c8cf0f7.

5. Webb Hooper, M., Nápoles, A. M., \& Pérez-Stable, E. J. (2020). COVID-19 and racial/ethnic disparities. Journal of the American Medical Association. https://doi.org/10.1001/jama.2020.8598.

6. Smith, D. A., Akira, A., Hudson, K., Hudson, A., Hudson, M., Mitchell, M., \& E. Crook (2017). The effect of health insurance coverage and the doctor-patient relationship on health care utilization in high poverty neighborhoods. Preventive Medicine Reports, 7, 158-161. https://doi.org/10.1016/j.pmedr.2017.06.002.

7. VanderWielen, L. M., Gilchrist, E. C., Nowels, M. A., Petterson, S. M., Rust, G., \& Miller, B. F. (2015). Not near enough: Racial and ethnic disparities in access to nearby behavioral health care and primary care. Journal of Health Care for the Poor And Underserved, 26(3), 1032-1047. https://doi.org/10.1353/hpu.2015.0083.
8. Cunningham, T. J., Croft, J. B., Liu, Y., Lu, H., Eke, P. I., \& Giles, W. H. (2017). Vital signs: Racial disparities in age-specific mortality among Blacks or African Americans-United States, 1999-2015. MMWR. Morbidity and Mortality Weekly Report, 66(17), 444-456. https://doi.org/10.15585/mmwr.mm6617e1.

9. Raifman, M. A.Raifman, J. R. (2020). Disparities in the population at risk of severe illness from COVID-19 by race/ethnicity and income. American Journal of Preventive Medicine, 59(1), 137-139. https://doi.org/10.1016/j.amepre.2020.04.003.

10. Blumenshine, P., Reingold, A., Egerter, S., Mockenhaupt, R., Braveman, P., \& Marks, J. (2008). Pandemic influenza planning in the United States from a health disparities perspective. Emerging Infectious Diseases, 14(5), 709-715. https://doi.org/10.3201/ eid1405.071301.

11. Watson, J. (2014). Young African American males: Barriers to access to health care. Journal of Human Behavior in the Social Environment, 24(8), 1004-1009. https://doi.org/10.1080/10911 359.2014.953416.

12. Cuevas, A. G., O’Brien, K., \& Saha, S. (2016). African American experiences in healthcare: "I always feel like I'm getting skipped over". Health Psychology, 35(9), 987.

13. Bailey, Z. D., Krieger, N., Agénor, M., Graves, J., Linos, N., \& Bassett, M. T. (2017). Structural racism and health inequities in the USA: Evidence and interventions. The Lancet, 389(10077), 1453-1463.

14. Yearby, R. (2018). Racial disparities in health status and access to healthcare: The continuation of inequality in the United States due to structural racism. American Journal of Economics and Sociology, 77(3-4), 1113-1152.

15. U.S. Census Bureau. (2021). QuickFacts: United States. Retrieved March 4, 2021, from https://www.census.gov/quickfacts/fact/ table/US/PST045219.

16. Centers for Disease Control and Prevention. (2021). Protect yourself: coronavirus disease (COVID-19). Retrieved February 4, 2021, from https://www.cdc.gov/coronavirus/2019-ncov/preve nt-getting-sick/prevention.html.

17. Rosenstock, I. M. (1990). The Health Belief Model: Explaining health behavior through expectancies. In K. Glanz, F. M. Lewis, \& B. K. Rimer (Eds.), Health behavior and health education: Theory, research, and practice (pp. 39-61). Jossey-Bass Publishers.

18. Rosenstock, I. M. (1974). The Health Belief Model and preventive health behavior. Health Education Monographs, 2(4), 354-386. https://doi.org/10.1177/109019817400200405.

19. Morovati, S. M., \& A.Rouhani, T. N. (2007). Perceived severity and susceptibility of diabetes complications and its relation to self-care behaviors among diabetic patients. Armaghan Danesh, 12(47), 59-67.

20. Lee-Won, R. J., Na, K., \& Coduto, K. D. (2017). The effects of social media virality metrics, message framing, and perceived susceptibility on cancer screening intention: The mediating role of fear. Telematics and Informatics, 34(8), 1387-1397. https://doi. org/10.1016/j.tele.2017.06.002.

21. Millett, G. A., Jones, A. T., Benkeser, D., Baral, S., Mercer, L., Beyrer, C., Honermann, B., Lankiewicz, E., Mena, L., Crowley, J. S., Sherwood, J., \& Sullivan, P. S. (2020). Assessing differential impacts of COVID-19 on Black communities. Annals of Epidemiology, 47, 37-44. https://doi.org/10.1016/j.annepidem.2020.05. 003.

22. Bailey, S. C., Serper, M., Opsasnick, L., Persell, S. D., O’Conor, R., Curtis, L. M., Benavente, J. Y., Wismer, G., Batio, S., Eifler, M., Zheng, P., Russell, A., Arvanitis, M., Ladner, D. P., Kwasny, M. J., Rowe, T., Linder, J. A., \& Wolf, M. S. (2020). Changes in COVID-19 Knowledge, beliefs, behaviors, and preparedness among high-risk adults from the onset to the acceleration phase of the US outbreak. Journal of General Internal Medicine, 35(11), 3285-3292. https://doi.org/10.1007/s11606-020-05980-2. 
23. U.S. Department of Agriculture. (2013). Rural-Urban Continuum Codes. Retrieved September 18, 2020, from https://www.ers.usda. gov/data-products/rural-urban-continuum-codes/documentation.

24. Alabama Center for Health Statistics. (2019). Alabama public health: Population by county and race -2019 . Retrieved January 25, 2021, from https://www.alabamapublichealth.gov/healthstats/ demographics.html.

25. Harris, P. A., Taylor, R., Thielke, R., Payne, J., Gonzalez, N., \& Conde, J. G. (2009). Research electronic data capture (REDCap) - A metadata-driven methodology and workflow process for providing translational research informatics support. Journal of Biomedical Informatics, 42(2), 377-381. https://doi. org/10.1016/j.jbi.2008.08.010.

26. Feick, L. F. (1989). Latent class analysis of survey questions that include don't know responses. Public Opinion Quarterly, 53(4), 525-547. https://doi.org/10.1086/269170.

27. Waters, E. A., Kiviniemi, M. T., Orom, H., \& Hay, J. L. (2016). "I don't know" my cancer risk: Implications for health behavior engagement. Annals of Behavioral Medicine, 50(5), 784-788. https://doi.org/10.1007/s12160-016-9789-5.

28. Orom, H., Biddle, C., Waters, E. A., Kiviniemi, M. T., Sosnowski, A. N., \& Hay, J. L. (2017). Causes and consequences of uncertainty about illness risk perceptions. Journal of Health Psychology, 25(8), 1030-1042. https://doi.org/10.1177/1359105317 745966.

29. SAS Institute Inc. (2013). SAS® 9.4. SAS Institute Inc.

30. Akokuwebe, M. E., Odimegwu, C., \& Omololu, F. (2020). Prevalence, risk-inducing lifestyle, and perceived susceptibility to kidney diseases by gender among Nigerians residents in South Western Nigeria. African Health Sciences, 20(2), 860-870. https:// doi.org/10.4314/ahs.v20i2.40.

31. Shahnazi, H., Hosseintalaei, M., Esteki Ghashghaei, F., Charkazi, A., Yahyavi, Y., \& Sharifirad, G. (2016). Effect of educational intervention on perceived susceptibility self-efficacy and DMFT of pregnant women. Iranian Red Crescent Medical Journal, 18(5), e24960-e24960. https://doi.org/10.5812/ircmj.24960.

32. Plough, A., Bristow, B., Fielding, J., Caldwell, S., \& Khan, S. (2011). Pandemics and health equity: Lessons LEARNED FROM the H1N1 response in Los Angeles County. Journal of Public Health Management and Practice, 17(1), 1-3.

33. Crouse Quinn, S. (2008). Crisis and emergency risk communication in a pandemic: A model for building capacity and resilience of minority communities. Health Promotion and Practice, 9(4_ suppl), 18S-25S. https://doi.org/10.1177/1524839908324022.

34. Ibuka, Y., Chapman, G. B., Meyers, L. A., Li, M., \& Galvani, A. P. (2010). The dynamics of risk perceptions and precautionary behavior in response to 2009 (H1N1) pandemic influenza. BMC Infectious Diseases, 10(1), 296. https://doi.org/10.1186/ 1471-2334-10-296.

35. Brug, J., Aro, A. R., Oenema, A., de Zwart, O., Richardus, J. H., \& Bishop, G. D. (2004). SARS risk perception, knowledge, precautions, and information sources, the Netherlands. Emerging Infectious Diseases, 10(8), 1486-1489. https://doi.org/10.3201/ eid1008.040283.
36. Cockerham, W. C. (2017). Medical Sociology (14th ed.). Prentice Hall.

37. Holland, D. J., Bradley, D. W., \& Khoury, J. M. (2005). Sending men the message about preventive care: An evaluation of communication strategies. International Journal of Men's Health, 4(2), 97-114.

38. Gast, J.Peak, T. (2010). It used to be that if it weren't broken and bleeding profusely, i would never go to the doctor": Men, masculinity, and health. American Journal of Men's Health, 5(4), 318-331. https://doi.org/10.1177/1557988310377926.

39. Margolis, R. (2013). Educational differences in healthy behavior changes and adherence among middle-aged Americans. Journal of Health and Social Behavior, 54(3), 353-368. https://doi.org/ 10.1177/0022146513489312.

40. Jansen, T., Rademakers, J., Waverijn, G., Verheij, R., Osborne, R., $\&$ Heijmans, M. (2018). The role of health literacy in explaining the association between educational attainment and the use of out-of-hours primary care services in chronically ill people: A survey study. BMC Health Services Research, 18(1), 394. https:// doi.org/10.1186/s12913-018-3197-4.

41. Friis, K., Lasgaard, M., Rowlands, G., Osborne, R. H., \& Maindal, H. T. (2016). Health literacy mediates the relationship between educational attainment and health behavior: A Danish populationbased study. Journal of Health Communication, 21(sup2), 54-60. https://doi.org/10.1080/10810730.2016.1201175.

42. Harper, C. A., Satchell, L. P., Fido, D., \& Latzman, R. D. (2020). Functional fear predicts public health compliance in the COVID19 pandemic. International Journal of Mental Health and Addiction. https://doi.org/10.1007/s11469-020-00281-5.

43. Bateman, L. B., Schoenberger, Y.-M. M., Hansen, B., Osborne, T. N., Okoro, G. C., Speights, K. M., \& Fouad, M. N. (2021). Confronting COVID-19 in under-resourced, African American neighborhoods: A qualitative study examining community member and stakeholders' perceptions. Ethnicity \& Health, 26(1), 49-67. https://doi.org/10.1080/13557858.2021.1873250.

44. Tomer, A., \& Kane, J. W. (2020). How to protect essential workers during COVID-19. Retrieved August 5, 2020, from https:// www.brookings.edu/research/how-to-protect-essential-worke rs-during-covid-19/.

45. Dhanani, L. Y.Franz, B. (2020). the role of news consumption and trust in public health leadership in shaping COVID-19 knowledge and prejudice. Frontiers in Psychology, 11, 2812.

46. Clark, C., Davila, A., Regis, M., \& Kraus, S. (2020). Predictors of COVID-19 voluntary compliance behaviors: An international investigation. Global Transitions, 2, 76-82. https://doi.org/10. 1016/j.glt.2020.06.003.

47. Shinan-Altman, S.Levkovich, I. (2020). COVID-19 precautionary behavior: The Israeli case in the initial stage of the outbreak. BMC public health, 20(1), 1718. https://doi.org/10.1186/ s12889-020-09818-8.

Publisher's Note Springer Nature remains neutral with regard to jurisdictional claims in published maps and institutional affiliations. 